\title{
Analysis of a Spiral/Spliced Pipe Weld Hydrostatic Test Rupture
}

\author{
J. L. McDougall *, F. E. Schmidt, Jr. ** and M. E. Stevenson * \\ * Engineering Systems Inc., 6109 Regency Parkway, Suite 316, Norcross, GA 30071 \\ ** Engineering Systems Inc., 3851 Exchange Drive, Aurora, IL 60504
}

A 36-inch spirally welded steel pipe failed during hydrostatic testing. The location of failure was determined to be at a splice weld between two different heats of steel coil, near the junction of the spiral weld. The API 5L X-70 specified steel was butt welded via a submerge arc process per an internal specification. No preheat or post-weld heat treatment was specified. Pressure testing was to be conducted at 154 bar for 20 seconds.

The client requested a root cause analysis including potential remediation. Initially the failure analysis was limited to a visual and microscopic evaluation utilizing both stereo and scanning electron microscopy (SEM). However, it was decided that metallography, calculation of carbon equivalent from composition data, and review of mechanical properties was necessary to fully understand the structure property performance issues.

Mechanical property and chemical composition requirements were fully met for both heats of steel. However, the carbon equivalent was sufficiently above 0.40 to be suspicious of post weld cracking. The actual calculated carbon equivalent values were 0.43 and 0.45 for the two heats. Possible evidence of HAZ cracking was observed associated with the inner diameter weld of the splice.

In conclusion, the presence of porosity, both macro wormhole and micro shrinkage associated with the fracture, initiated the rupture. However the presence of moisture as a consequence of no preheating may also have been a contributing factor to the entrapped gas generation. The presence of localized discoloration associated with the fracture origin also suggests incomplete weld penetration; evidence of modest weld penetration was observed adjacent to the fracture origin. Although strong evidence of HAZ cracking was not observed, the client was advised to pay closer attention to the carbon equivalent values when making the determination to utilize preheating and/or post-weld heat treatment.

FIG. 1. Macro evaluation of the pipe rupture in splice weld, arrow denotes porosity

FIG. 2. Composite stereomicroscope of the fracture origin

FIG. 3. Macro etch of splice weld with modest penetration (Nital 3\%)

FIG. 4. Evidence of possible HAZ cracking (Nital 3\%)

FIG. 5. SEM micrograph of macro porosity

FIG. 6. SEM micrograph of macro porosity and shrinkage porosity

FIG. 7. SEM micrograph of shrinkage porosity

FIG. 8. SEM micrograph of shrinkage porosity

[1] D.G. Brandon, et al., Joining Processes: an introduction. John Wiley \& Sons Ltd., West Sussex, 1997.

[2] Sindo Kou, Welding Metallurgy, $2^{\text {nd }}$ Edition. John Wiley \& Sons, Inc., Hoboken, 2003.

[3] ASM International, ASM Handbook, Vol. 6: Welding, Brazing, and Soldering, 379-380, ASM International, Materials Park, 1993. 

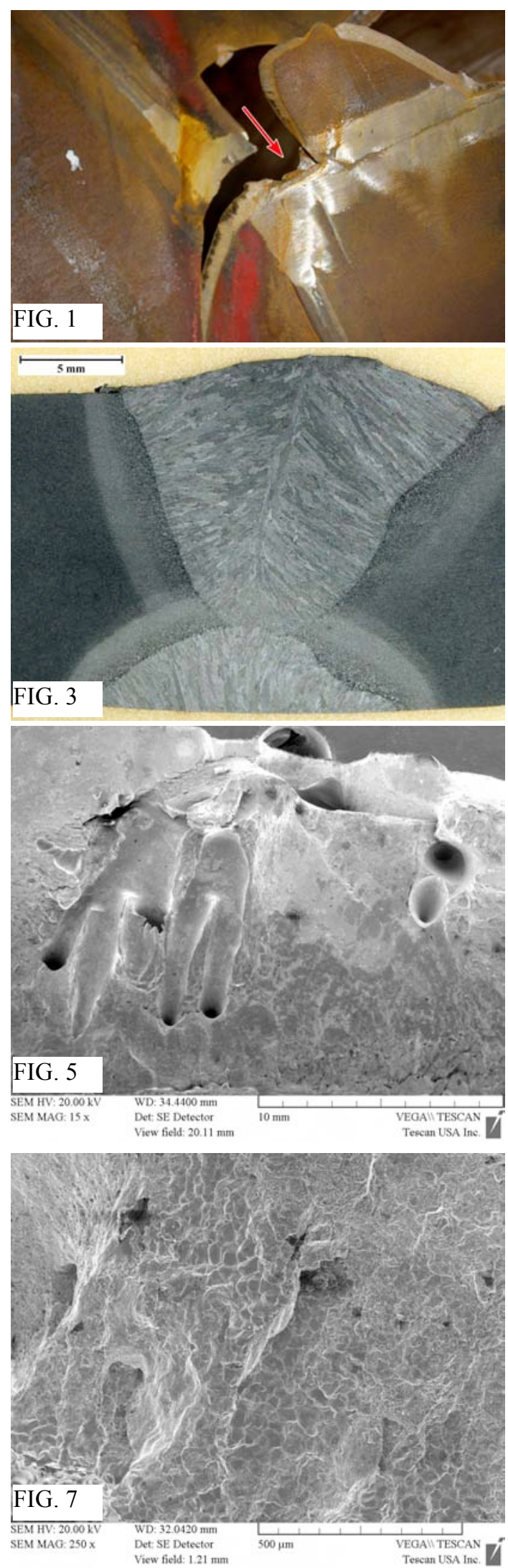
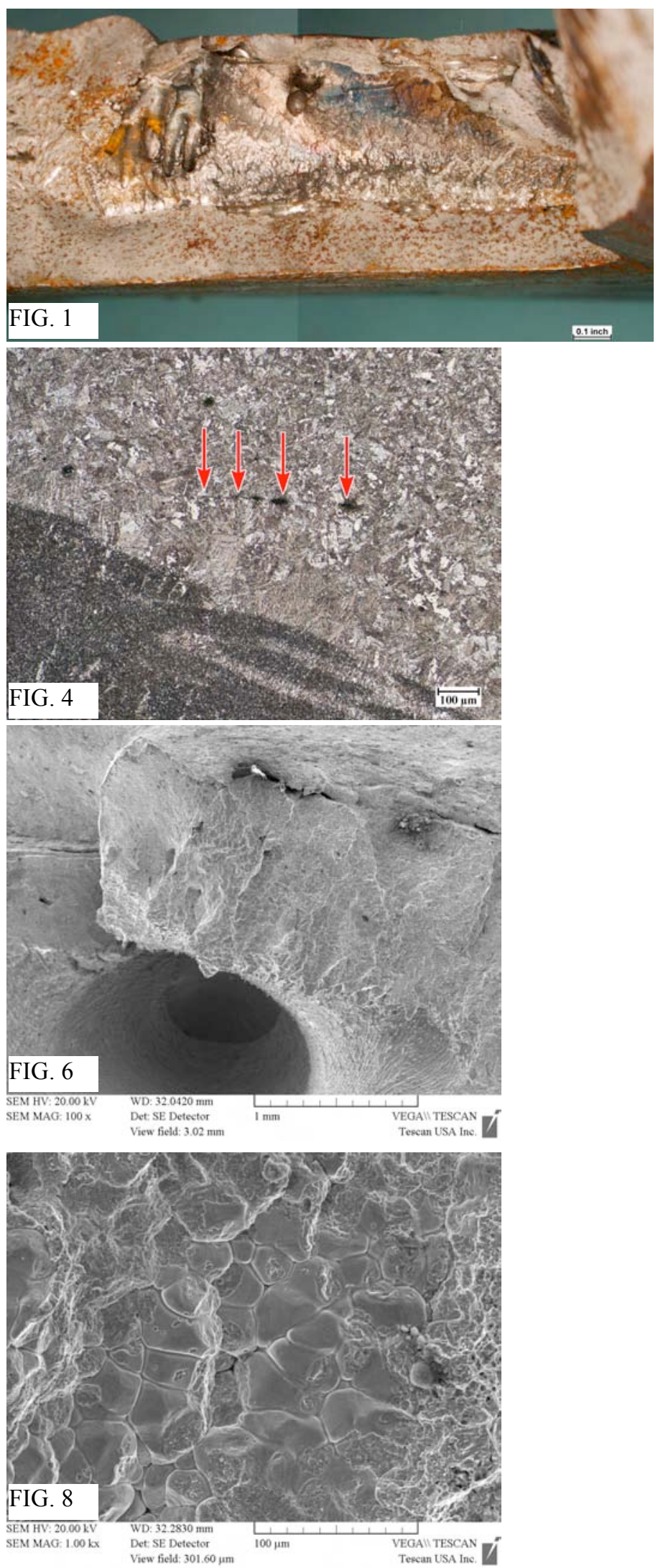